\title{
A variable limit for the instability parameter of wall-frame or core-frame bracing structures
}

\section{Um limite variável para o parâmetro de instabilidade de estruturas de contraventamento formadas por associações de pórticos com paredes ou núcleos}

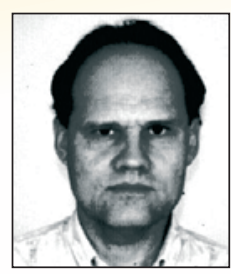

R. J. ELLWANGER a rjellwanger@pop.com.br

\begin{abstract}
This work aims to investigate the viability and convenience of adopting a variable limit $\alpha_{1}$ for the instability parameter of buildings with reinforced concrete wall-frame or core-frame structures. Initially, the evolution of tall buildings global stability theory is summarized, giving emphasis to define when a second order analysis is needed. The treatment given to this subject by the present Brazilian code for concrete structures design (NBR 6118:2007) is also showed. It follows a detailed analytical study that led to the derivation of an equation for the variable limit $\alpha_{1}$; a series of examples is presented to check its accuracy. Results are analyzed, showing the validity bounds of the equation and research directions are suggested, in order to improve it.
\end{abstract}

Keywords: instability, bracing structures, second order.

\section{Resumo}

O presente trabalho tem por objetivo investigar a viabilidade e a conveniência de se adotar um limite variável $\alpha$, para o parâmetro de instabilidade de edifícios com estruturas de concreto armado, constituídas por associações de pórticos com paredes ou núcleos. Inicialmente, é feito um resumo da evolução da teoria sobre a análise da estabilidade global de edifícios altos, especialmente sobre a definição da necessidade ou não de se realizar uma análise de segunda ordem; mostra-se também como esta questão é tratada pela atual norma de projeto de estruturas de concreto (NBR 6118:2007). Na seqüência, apresenta-se um detalhado estudo analítico que levou ao estabelecimento de uma fórmula para o limite variável $\alpha_{1}$, seguido de uma série de exemplos para testar a validade da mesma. Os resultados são analisados, mostrando-se os limites de validade da fórmula e indicando-se linhas de investigação no sentido de aperfeiçoá-la.

Palavras-chave: instabilidade, estruturas de contraventamento, segunda ordem.

Professor Associado, Departamento de Engenharia Civil, Universidade Federal do Rio Grande do Sul, e-mail: rjellwanger@pop.com.br, endereço postal: Rua Marcelo Gama 1189/401, CEP 90540-041, Porto Alegre-RS, Brasil. 


\section{Introduction}

\subsection{Second order effects in building structures}

Depending on its flexibleness, a building bracing structure, when simultaneously subject to gravity and wind loads, may develop additional effects to those usually obtained in a first order linear analysis (in which the equilibrium is verified in the non deformed structure). They are the second order effects, in whose computation the material nonlinear behavior (physical nonlinearity) and the structure deflected shape (geometric nonlinearity) must be considered.

The work of Beck and König [1], brought in 1967, represented an important advance in the development of tall buildings global stability analysis. A very easy criterion to apply was established, determining that the second order effects may be neglected, provided that they don't represent an increase more than $10 \%$ on the first order effects. Figure 1 shows the simplified model for the bracing system. At first, all bracing substructures are grouped in a single column, while all braced elements (bearing elements that don't belong to the bracing system) are replaced by an assemblage of hinged bars, as shown in figure 1-a. The wind is considered by means of a $w$ rate uniform load. $P$ and $V$ are the floor vertical loads, applied on the bracing substructures and braced elements, respectively. The loads $w, P$ and $V$ are considered with their characteristic values. Thereafter, in order to make possible to determine the second order effects by means of a continuum analysis, an equivalent approximate model, shown in figure $1-b$, is adopted, with a continuous and uniform distribution of floors and vertical loads $(p=P / h$ e $v=V / h)$.

Concerning to the influence of the loads $V$, acting on the braced elements, Beck and König [1] proved that, when the system distorts laterally, horizontal forces are transmitted through the floor members to the bracing system, increasing the bending moment on its support. It can be proved that this increase is given by the sum of the forces $V$ multiplied by the horizontal displacements of the respective floors. Therefore, in order to compute this bending moment including second order effects, the vertical loads acting on the bracing system would be given by the sum of its proper $P$ loads and $V$ loads.

In 1978, the criterion proposed by Beck and König [1] was included in the Comité Euro-International du Béton recommendations (CEB [2]). Its application consists in comparing the global bending moments at the bracing system support $M^{\prime}$ (considering only first order effects) and $M$ " (including second order effects):

$$
M^{I I} \leq 1,1 M^{I}
$$

or

$$
\frac{1,75 w H_{t o t}^{2}}{2} \cdot \frac{1}{1-\frac{1,75(p+v) H_{t o t}^{3}}{8 E J}} \leq 1,1 \times 1,75 \frac{w H_{t o t}^{2}}{2}
$$

It can be noted that $M^{\prime}$ and $M$ " are due to factored loads, since the rates $w, p$ and $v$ are multiplied by 1,75 . On the other hand, the physical nonlinearity is regarded taking $E J=0,7 E_{c m} J$ for the structural members, where $E_{\mathrm{cm}} J$ represents the sum of the bracing substructures stiffness coefficients at the non cracked stage. Thus, performing this substitution leads to the condition:

\section{Figure 1 - Simplified model for the bracing system}
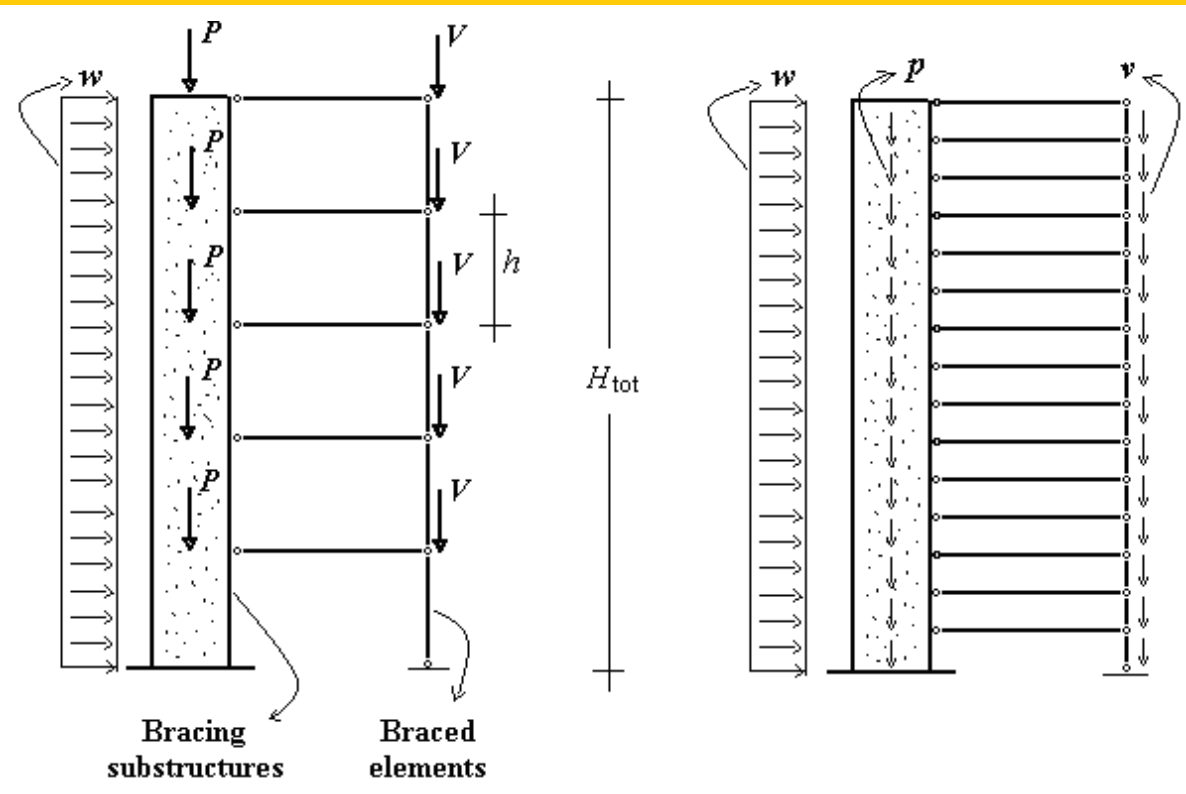


$$
H_{\text {tot }} \sqrt{(p+v) H_{\text {tot }} /\left(E_{\mathrm{cm}} J\right)} \leq 0,54
$$

According to Vasconcelos [3], the results obtained by Beck and König [1] could be applied only to building structures whose lateral stiffness was concentrated in few columns rigidly connected among themselves, in order to be considered as a single column. The correspondence of this model with other types of bracing systems (variable section walls, rigid frames etc.) came to be done through the equality of horizontal displacements due to horizontal loads. The equivalent column would be that one with a stiffness factor EJ such that the resulting horizontal displacements were the same of the structure under consideration, for the same horizontal loading. With the purpose of simplification, this equivalent stiffness came to be determined based on the actuation of a unit horizontal load at the building top. In Brazil, the procedure came to be applied changing the load factor from 1,75 to 1,40 - see, for example, Sussekind [4] - and came to be known as minimal stiffness check. Consequently, inequality (3) changed to:

$$
H_{\text {tot }} \sqrt{(p+v) H_{\text {tot }} /\left(E_{\mathrm{S}-28} J_{\mathrm{I}}\right)} \leq 0,60
$$

where $E_{\mathrm{s}-28}$ is the concrete secant elasticity modulus at 28 days and $J_{1}$ is the sum of bracing substructures inertias at non cracked stage.

In 1985, Franco [5] proposed that the equivalent column stiffness have to be obtained based on the actuation of a uniformly distributed horizontal load, in place of the top unit load. Furthermore, he preconized that the deflected shape of the bracing structure can affect the Beck and König [1] criterion application. Thus, the coefficient on the inequality (4) right hand would have its value defined as a function of the bracing type:

- walls or cores: coefficient 0,7 ;

- wall-frame or core-frame structures: coefficient 0,6;

- only rigid frames: coefficient 0,5 .

In 1995, Franco [6], dealing with the physical nonlinearity consideration through structural members stiffness reduction, proposed different reduction factors, specific for slabs, column members and beam members with symmetrical and asymmetrical reinforcement. Although not belonging to this work purpose, a mention deserves to be made to the method based on the moment amplification factor $\gamma_{z}$, presented in 1991 by Franco and Vasconcelos [7]. It also applies the criterion of $10 \%$ increase in relation to first order effects, to define if a second order analysis is or not needed; however, in this case it is done for each combination of horizontal and vertical loads. Furthermore, under certain conditions, this method may itself constitute a second order analysis. These features caused this method to be rapidly disseminated and largely employed in buildings structures design.

\subsection{ABNT NBR 6118 prescriptions}

The ABNT NBR 6118 [8], present Brazilian code for concrete structures design, adopted the fundamental idea presented in [1] and
[2], on determining in its section 15 that the second order global effects are negligible when lower than $10 \%$ of the respective first order effects (fixed nodes structure). In order to "verify the possibility of dispensing the consideration of second order global efforts, in other words, to define if the structure may be classified as a fixed nodes one, without the need of a rigorous analysis", ABNT [8] presents two approximate procedures, based respectively on the instability parameter and the $\gamma_{z}$ factor. The first one just consists of the Beck and König [1] criterion application and determines that: "A symmetrical framed structure may be considered as a fixed nodes one, if its instability parameter a will be lesser than the $\alpha_{1}$ value, according to the expressions:

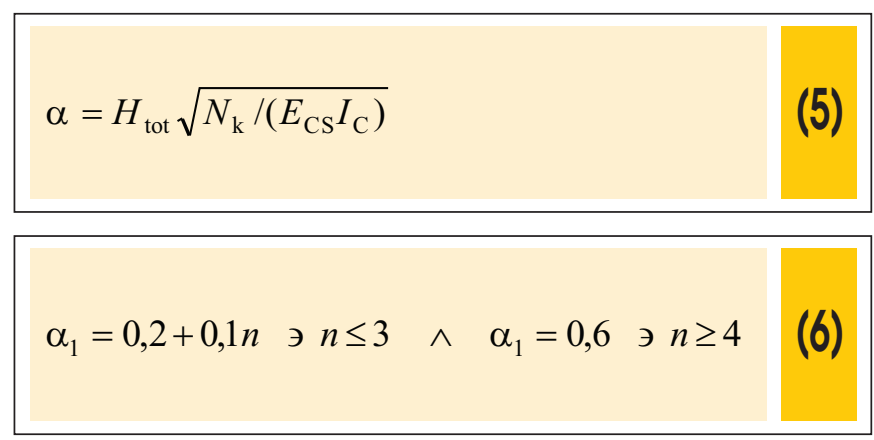

" $n$ is the number of horizontal bars levels (floors) above the foundation or a slightly displaceable subsoil level. $H_{\text {tot }}$ is the structure total height, measured from the foundation top or a slightly displaceable subsoil level. $N_{\mathrm{k}}$ is the summation of all vertical loads acting on the structure (from the level considered for $H_{\text {tot }}$ computation), with their characteristic values. $E_{c s} I_{C}$ represents the summation of all column stiffness values in the considered direction. In the case of framed, trussed or mixed structures, or columns with variable stiffness along the height, the $E_{c s} I_{c}$ value of an equivalent column with constant section may be considered". The determination of this equivalence will be seen in section $2.1 . I_{C}$ is the moment of inertia considering columns gross sections. $E_{C S}$ is the secant elasticity modulus, expressed by:

$$
E_{C S}=0,85 E_{C i}=0,85 \times 5600 f_{c k}^{1 / 2}
$$

$E_{\mathrm{cS}}, \mathrm{E}_{\mathrm{Ci}}$ (tangent elasticity modulus) and $f_{\mathrm{ck}}$ (compressive characteristic strength) are given in MPa. The NBR 6118 code also adopted the Franco [5] propositions on determining different $\alpha_{1}$ values, depending on the bracing structure type: "The limit value $\alpha_{1}=$ 0,6 , prescribed for $n \geq 4$, is generally applicable to the building usual structures. It may be adopted for wall-columns assemblages and rigid frames associated to wall-columns. It may be increased until $\alpha_{1}=0,7$ in the case of bracing systems composed exclusively by wall-columns and must be reduced to $\alpha_{1}=0,5$ if there are only rigid frames."

In a second order analysis, the effects of both physical and geometric nonlinearities must be considered. ABNT [8], in its item 15.7.3, allows that the physical nonlinearity can be considered in an approximated manner, on calculating second order global efforts in framed structures with four or more floors. This is done by means of a reduction of the structural members $(E I)_{\mathrm{sec}}$ stiffness factors as 
a function of $E_{\mathrm{Ci}} I_{C}$, or of $E_{\mathrm{CS}} I_{\mathrm{C}}$ if equation (7) is used. Representing by $A_{\mathrm{s}}$ and $A_{\mathrm{s}}$, , respectively, the tensile and compressive longitudinal reinforcements areas, the following expressions can be written: - slabs:

$(E I)_{\mathrm{sec}}=0,3 E_{C i} I_{C}=0,353 E_{C S} I_{C}$

- beams:

$$
(E I)_{\mathrm{sec}}=0,4 E_{C i} I_{C}=0,471 E_{C S} I_{C} \quad \ni A_{s} \neq A_{s}^{\prime}
$$

$$
(E I)_{\mathrm{sec}}=0,5 E_{C i} I_{C}=0,588 E_{C S} I_{C} \quad \ni A_{s}=A_{s}^{\prime} \quad \text { (10) }
$$

- columns:

$$
(E I)_{\mathrm{sec}}=0,8 E_{C i} I_{C}=0,941 E_{C S} I_{C}
$$

Furthermore, when the bracing substructure is exclusively constituted by beams and columns (rigid frame) and the "importance factor" of the second order global efforts $\left(\gamma_{z}\right)$ is lesser than 1,3 (corresponding to a "bland" nonlinearity) it is allowed to consider the stiffness of the rigid frame members as a whole, as follows:

$$
(E I)_{\mathrm{sec}}=0,7 E_{C i} I_{C}=0,824 E_{C S} I_{C}
$$

\subsection{Reasons and targets of the research}

The ABNT [8] code represented an improvement in relation to the preceding one, on establishing procedures for checking if second order global effects are unnecessary to consider. Concerning to the instability parameter for buildings with four or more floors, it treated differently the various types of bracing systems, on determining different values for the $\alpha_{1}$ limit. However, the prescription of a fixed limit $\left(\alpha_{1}=0,6\right)$ for associations of walls and/or cores with rigid frames is questionable. As the relation between the stiffness factors of walls/cores and frames can vary, $\alpha_{1}$ also can vary from 0,5 to 0,7 . This can lead to two types of errors:

- on behalf of safety: in associations with predominance of walls/ cores, the code restricts $\alpha_{1}$ to 0,6 , when a larger value, possibly close to 0,7 , could be adopted;

- contrary to safety: in the case of associations with predomi- nance of frames, when a value lesser than 0,6 , possibly close to 0,5 , should be adopted.

These errors, if expressed in relation to $\alpha_{1}$, are apparently small. However, is must be remembered that the instability parameter computation requires a square root extraction. Consequently, on verifying the exemption of performing a second order analysis, the error on determining the needed stiffness can become significant. This work aims to research a way of defining the instability parameter limit $\alpha_{1}$ for associations of rigid frames and walls/cores, variable with their stiffness factors proportion. At first, the linear behavior formulation for these associations is presented, followed by an analytical study about the geometric nonlinear behavior of isolated walls/cores and rigid frames and then of their association. This study is based on the simplified model presented in section 1.1, applying the criterion expressed by inequality (1); the differential equations are solved by Galerkin method. Right away, the formula found for the variable limit $\alpha_{1}$ is tested in a series of examples of buildings braced by wall-frame associations. 88 tests are performed, varying the number of floors, of frame spans and the proportion between the stiffness factors of frames and walls.

\section{Linear analysis}

\subsection{Equivalence between bracing substructures}

The substructures of the wall or core types distinguish themselves by a high stiffness to shear, predominating flexural deflections. They may be modeled by simple beams, fixed on the building support, behaving as columns. Figure 2-a shows a wall or core, modeled by a cantilever bar of length $\ell$, subject to an uniformly distributed horizontal load of ratio $w$. Representing the material longitudinal elasticity modulus, the constant section moment of inertia and the bending moment function respectively by $E, J$ and $M(x)$, the differential equation of motion may be expressed as:

$$
E J d^{2} y / d x^{2}=E J d \phi / d x=M(x)=w(\ell-x)^{2} / 2
$$

Bending moments inducing tension on the bar left side are positive, the deflected concavity becoming turned to right $(\phi(x)$ is its slope). Introducing the appropriate boundary conditions, $y(x)$ and the top horizontal displacement $\Delta_{H}$ are obtained:

$$
y(x)=\frac{w \ell^{4}}{24 E J}\left[\left(1-\frac{x}{\ell}\right)^{4}+\frac{4 x}{\ell}-1\right]
$$

$$
\Delta_{H}=y(\ell)=w \ell^{4} / 8 E J
$$

In substructures of the rigid frame type, the deflections due to bending of the individual beam and column members are predominant. When the frame is subject to horizontal loads, the global bending moment is mainly carried to the columns as axial efforts, for which 


\section{Figure 2 - Bracing substructure equivalent bars}

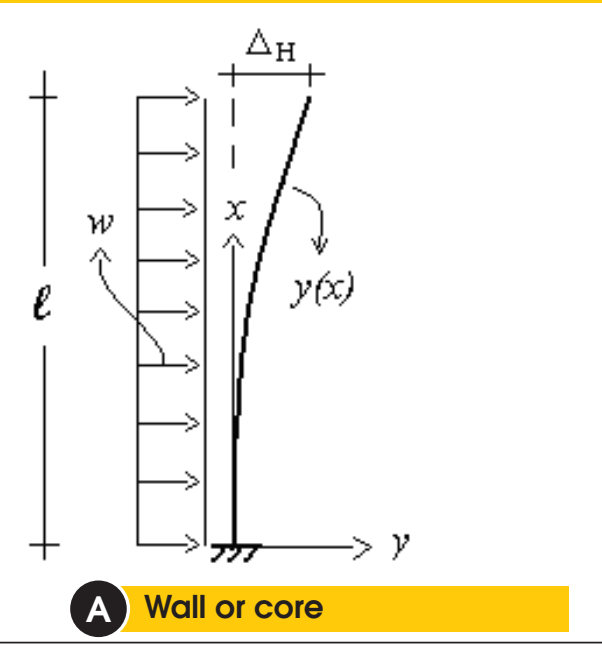

the structure has a high stiffness. The horizontal deflections are mostly caused by global shear. Therefore, the rigid frames may be modeled as vertical bars extremely stiff to global bending, prevailing shear distortions.

Figure 2-b shows a rigid plane frame subject to an uniformly distributed horizontal load of ratio $w$. It is modeled by a vertical bar predominantly deformable by shear. As shown in the figure, the deflected shape of this bar characterizes itself by a maximum $\phi(x)$ slope at basis and tending to zero at top, just the contrary that happens to the bar simulating the wall or core. This slope is related with the differences between horizontal displacements at adjacent floors. In their turn, these differences are proportional to the global shear $Q(x)$. According to Stamato [9], the deflected shape for this case is described by the following equation:

$$
S d y / d x=S \phi(x)=Q(x)=w(\ell-x)
$$

The proportionality factor $S$ represents the system (plane frame) stiffness to global shear; it corresponds to the $G A$ / $c$ factor of a bar with shear deformation, where $G, A$ and $c$ are, respectively, the shear modulus, the section area and the section shape factor. Solving equation (16), $y(x)$ is obtained, leading to the top horizontal displacement:

$$
\Delta_{H}=y(\ell)=w \ell^{2} / 2 S
$$

The relations established in this section have as their purpose to obtain the inertia of a bar equivalent to a given rigid plane frame. The item 15.5.2 of ABNT [8] code, on dealing with the instability parameter, establishes a methodology to determine the $E_{c s} I_{C}$ factor of a constant section column, equivalent to a given rigid plane frame. According to this methodology, the above-mentioned stiff-

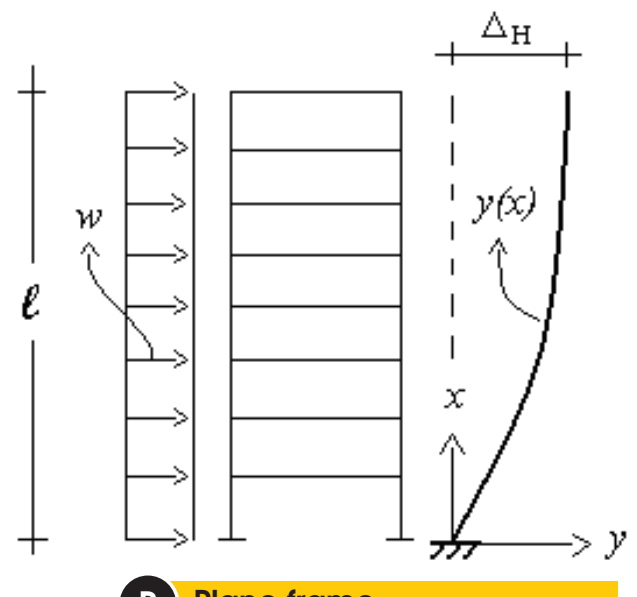

ness factor should be obtained computing initially the horizontal displacement on the bracing structure (frame) top, under the horizontal loading, which is just $\Delta_{H}$ given by (17). The next step is to obtain the stiffness of an equivalent column with constant section such that, under the same loading, undergoes the same top horizontal displacement which, in this case, is $\Delta_{H}$ given by (15). This implies in equality between the two expressions for $\Delta_{\mathrm{H}}$, resulting:

$$
S=4 E J / \ell^{2}
$$

\subsection{Association of rigid frames with walls and/or cores}

This section presents the formulation of the linear response of frame-wall/core structures, in order to that it have further on to be used by Galerkin method in obtaining an approximate solution for the nonlinear behavior of these structures. Figure 3-a shows the simplified model of a bracing system composed by substructures of the frame and wall/core types. The model consists in a wall (representing all system walls and cores) and a rigid frame (representing all system frames) connected among themselves by hinges (representing the floor slabs). An uniform distribution of rate $w$ is admitted for the wind loads. $E J_{1}$ represents the stiffness of the frames set, according to equation (18). $E J_{2}$ represents the stiffness of the walls/cores set.

Figures 3-b and 3-c show the loads to that the wall and the frame will respectively be subject. These loads consist in top concentrated forces $\left(Q_{T}\right.$ for the frame and $-Q_{T}$ for the wall) and distributed forces that can be decomposed in constant and variable (along the height) parcels. The constant parcels ( $w_{1}$ for the frame and $w_{2}$ for the wall) are such that $w_{1}+w_{2}=w$. The variable parcels (rate $\left(u(x)\right.$ for the frame and $-u(x)$ for the wall), jointly with the forces $Q_{T}$, represent internal forces originated from the wall-frame interaction; since they are connected by the hinges, the wall and the frame 


\section{Figure 3 - Association of rigid frames with walls or cores}

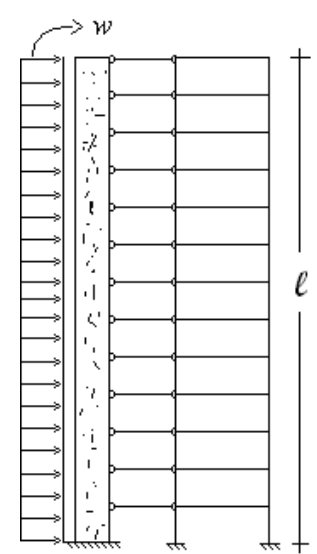

a

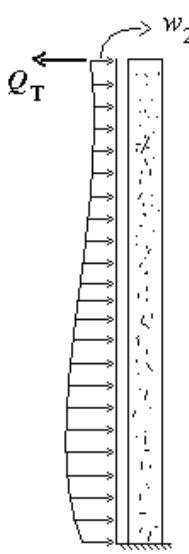

b

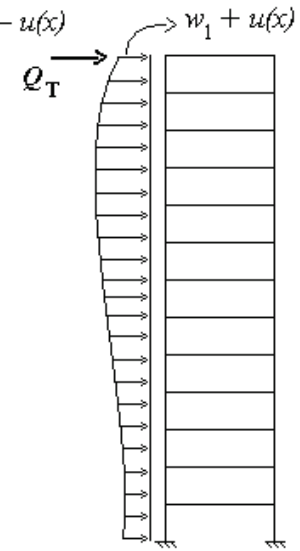

c

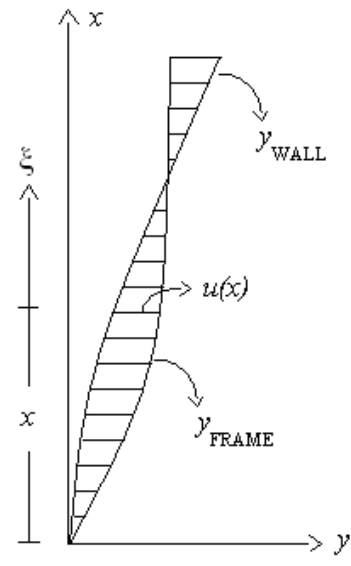

d are impeded to develop their natural deflected shapes, as shown in figure 3-d. The frame will be subject to a global shear forces distribution given by:

$$
Q(x)=w_{1}(\ell-x)+Q_{T}+\int_{x}^{\ell} u(\xi) d \xi
$$

As was seen in section 2.1, the frame behavior is described by equation (16). Writing this equation, introducing (18) and (19) and isolating the terms regarding to the internal forces, gives:

$$
Q_{T}+\int_{x}^{\ell} u(\xi) d \xi=\frac{4 E J_{1}}{\ell^{2}} \phi(x)-w_{1}(\ell-x)
$$

In its turn, the wall will be subject to a bending moments distribution given by:

$$
M(x)=w_{2}(\ell-x)^{2} / 2-Q_{T}(\ell-x)-\int_{x}^{\ell} u(\xi)(\xi-x) d \xi
$$

As was also seen in section 2.1, the wall behavior is described by equation (13). Writing this equation, introducing $M(x)$ given by (21) and deriving both members, gives successively:

$$
E J_{2} \frac{d \phi}{d x}=w_{2}(\ell-x)^{2} / 2-Q_{T}(\ell-x)-\int_{x}^{\ell} u(\xi)(\xi-x) d \xi
$$

$$
E J_{2} \frac{d^{2} \phi}{d x^{2}}=-w_{2}(\ell-x)+Q_{T}+\int_{x}^{\ell} u(\xi) d \xi
$$

Substituting (20) into (23) and re-arranging:

$$
E J_{2} \frac{d^{2} \phi}{d x^{2}}-\frac{4 E J_{1}}{\boldsymbol{\ell}^{2}} \phi(x)+w_{1}(\ell-x)+w_{2}(\ell-x)=0
$$

Considering that $w_{1}+w_{2}=w$ (total wind load acting on the system) and defining a new variable $K=\sqrt{J_{1} / J_{2}}$, the solution for equation (24) may be expressed as follows:

$$
\phi(x)=C_{1} e^{2 K x / \ell}+C_{2} e^{-2 K x / \ell}+\frac{w \ell^{2}}{4 E J_{1}}(\ell-x)
$$

where

$$
C_{1}=\frac{w \ell^{3}}{8 E J_{1} K} \frac{\mathrm{e}^{2 K}-2 K}{\mathrm{e}^{4 K}+1}
$$

$$
C_{2}=\frac{-w \ell^{3}}{8 E J_{1} K} \frac{2 K \mathrm{e}^{4 K}+\mathrm{e}^{2 K}}{\mathrm{e}^{4 K}+1}
$$




\section{The Galerkin method}

In many engineering problems, as the ones that are presented in the next sections, there arises the need to solve an equation of the type $L(y)=0$, where $L$ is a differential operator, whose solution satisfies to homogeneous boundary conditions. The Galerkin method consists in obtaining an approximate solution of the form:

$$
\bar{y}(x)=\sum_{i=1}^{n} a_{\mathrm{i}} \varphi_{\mathrm{i}}(x)
$$

where $\varphi_{\mathrm{i}}(x)(i=1,2, \ldots, n)$ are functions, previously chosen and satisfying to the same boundary conditions; the $a_{\mathrm{i}}$ are coefficients to be determined. The $n$ functions $\varphi_{\mathrm{i}}(x)$ must be linearly independent and belong to a system, represented by $\left\{\varphi_{\mathrm{i}}(x)\right\}$ ( $i$ $=1,2, \ldots, n)$ and endowed of the completeness property in the solution domain. In order to $y(x)$ be the exact solution of the given equation, it is necessary that $L(y)$ be identically null. This requirement, if $L(y)$ is considered to be continuous, is equivalent to the requirement of the orthogonality of the expression $L$ ( $y)$ to all the functions $\varphi_{\mathrm{i}}(x)(i=1,2, \ldots, n)$. However, having at disposal only $n$ constants $a_{i}$, only $n$ orthogonality conditions can be satisfied. Applying these conditions, the following system of equations is obtained:

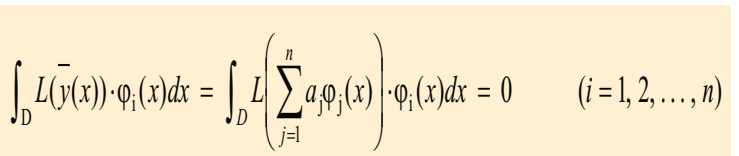

The solution of this system (a linear one, in the case of a linear operator $L$ ) provides the values of the coefficients $a_{i}$, from which the approximate solution $y(x)$ is obtained. The proof of convergence, as well as more detailed considerations about the Galerkin method can be seen in Kantorovich and Krylov [10].

\section{Exemption of the second order effects consideration}

The sections 4.1 and 4.2 present the formulation of the geometric nonlinear behavior, respectively of wall/cores and rigid frames assemblages. For both cases, the limits $\alpha_{1}$ of the instability parameter are deduced, comparing them with the values prescribed by ABNT [8] code. The section 4.3 does the same for the associations of these types of substructures, obtaining an expression for the variable limit $\alpha_{1}$, main objective of this work.

Figure 4-a shows the deflected shape of a bar equivalent to a bracing system, subject to uniformly distributed loads of rates $w$ and $q$, respectively in the horizontal and vertical directions; $q$ is given by the sum of the rates $p$ and $v$ of figure 1-b. Taking into account the bar deflections (geometric nonlinearity) and representing by $Y$ the primitive function of the displacements $y(x)$, the bending moment will be given by:

$$
M(x)=w(\ell-x)^{2} / 2+\int_{x}^{\ell} q[y(\xi)-y(x)] d \xi
$$

or

$$
M(x)=w(\ell-x)^{2} / 2+q[Y(\ell)-Y(x)-(\ell-x) y(x)]
$$

Considering that $y(0)=0$, the bending moment at support will be expressed by:

$$
M(0)=w \ell^{2} / 2+q[Y(\ell)-Y(0)]
$$

\section{Figure 4 - Deformations influence in the structure response}

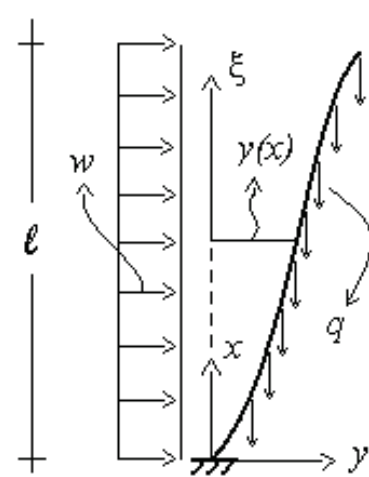

(A)

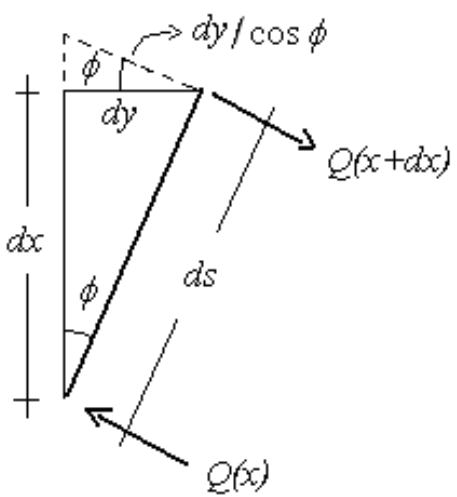

B Shear deformation at the infinitesimal level 


\subsection{Substructures of shear wall or shear core types}

In the case of bracing systems formed exclusively by shear walls and/or shear cores, the differential equation of motion will be obtained equalizing $E J d^{2} y / d x^{2}$ to $M(x)$ given by (31):

$$
E J d^{2} y / d x^{2}=w(\ell-x)^{2} / 2+q[Y(\ell)-Y(x)-(\ell-x) y(x)]
$$

Deriving it in relation to $x$ and considering that the rotations are given by $\phi(x)=d y / d x$, changes equation (33) into:

$$
E J d^{2} \phi / d x^{2}+q(\ell-x) \phi(x)+w(\ell-x)=0
$$

An approximate solution for equation (34) can be obtained through the Galerkin method. Assuming that this solution is proportional to $\phi(x)$ due exclusively to first order effects, it may be written:

$$
\phi(x)=a_{1} \varphi_{1}(x)=a_{1}\left[1-\left(1-\frac{x}{\ell}\right)^{3}\right]
$$

where $\varphi_{1}(x)$ was obtained deriving equation (14) in relation to $x$ and suppressing the constant that would remain in evidence. Applying equation (29) with $n=1$, leads successively to:

$$
\begin{aligned}
& \int_{0}^{\ell} L(\phi) \cdot \varphi_{1}(x) d x=\int_{0}^{\ell} L\left(a_{1} \varphi_{1}(x)\right) \cdot \varphi_{1}(x) d x=0 \\
& \int_{0}^{\ell}\left\{\frac{6 E J a_{1}}{\ell^{2}}\left(\frac{x}{\ell}-1\right)+q(\ell-x) a_{1}\left[1-\left(1-\frac{x}{\ell}\right)^{3}\right]+w(\ell-x)\right] \cdot\left[1-\left(1-\frac{x}{\ell}\right)^{3}\right] d x=0
\end{aligned}
$$

Performing the integration and isolating $a_{1}$, results:

$$
a_{1}=\frac{4 w \ell^{3}}{24 E J-3 q \ell^{3}}
$$

On substituting (38) into (35), the approximate solution is obtained:

$$
\phi(x)=\frac{4 w \ell^{3}}{24 E J-3 q \ell^{3}}\left[1-\left(1-\frac{x}{\ell}\right)^{3}\right]
$$

Integrating (39) in relation to $x$ and applying the condition of zero displacement at support, leads to the displacements function. Integrating again, leads to:

$$
Y(x)=\frac{w \ell^{4}}{24 E J-3 q \ell^{3}}\left[-\frac{\ell}{5}\left(1-\frac{x}{\ell}\right)^{5}+\frac{2 x^{2}}{\ell}-x\right]+C
$$

where $C$ is the integration constant. The bending moment at support can be obtained on applying equations (32) and (40):

$$
M(0)=\frac{w \ell^{2}}{2}+\frac{2 q w \ell^{5}}{5\left(8 E J-q \ell^{3}\right)}
$$

Equation (41) can be transformed successively into:

$$
M(0)=\frac{w \ell^{2}}{2} \cdot\left(1+\frac{4 q \ell^{3}}{5\left(8 E J-q \ell^{3}\right)}\right)=\frac{w \ell^{2}}{2} \cdot \frac{8 E J-q \ell^{3} / 5}{8 E J-q \ell^{3}}
$$

The condition of that, in the ultimate limit state (loads multiplied by $1,4)$, the second order effects may not exceed the first order effects in more than $10 \%$ (inequality (1)), is applied to the support bending moment, obtaining:

$$
\frac{1,4 w \ell^{2}}{2} \times \frac{8 E J-1,4 q \ell^{3} / 5}{8 E J-1,4 q \ell^{3}} \leq 1,1 \times \frac{1,4 w \ell^{2}}{2}
$$

The terms $\boldsymbol{w} \boldsymbol{\ell}^{2}$, multiplying both sides of the inequality, do vanish. Performing the required algebraic transformations, results:

$$
q \ell^{3} / E J \leq 0,6349
$$

Since a wall or core has a behavior equivalent to the one of a column, the physical nonlinearity may be considered adopting for $E J$ the expression $0,941 E_{c s} I_{c}$, according to equation (11). On the other hand, remembering that $q \ell$ is the total vertical load $N_{\mathrm{k}}$ and $\ell$ is the total height $H_{\text {tot }}$, inequality (44) becomes:

$$
H_{\mathrm{tot}}^{2} \times N_{\mathrm{k}} / E_{\mathrm{CS}} I_{\mathrm{C}} \leq 0,5974
$$

Extracting the square root of both members:

$$
H_{\text {tot }} \times \sqrt{N_{\mathrm{k}} / E_{\mathrm{CS}} I_{\mathrm{C}}} \leq 0,773
$$


Thus, inequality (46) denotes a value of 0,773 for $\alpha_{1}$. In its turn, the ABNT [8] code allows the coefficient $\alpha_{1}$ to be increased until 0,7 if the bracing system is composed exclusively by shear walls or shear cores.

\subsection{Substructures of the rigid plane frame type}

In the case of bracing systems formed exclusively by rigid frames, the equivalent bar of figure 4-a will deform predominantly by shear. Also in this case, the efforts expression must take the deflected shape into account. It can be proved that the infinitesimals $d s$ and $d x$ shown in figure 4-b are related by:

$$
d s=\sqrt{d x^{2}+d y^{2}}=\sqrt{d x^{2}\left(1+d y^{2} / d x^{2}\right)}=d x \sqrt{1+\phi^{2}}
$$

The shear effort can be obtained from the derivation of equation (31) in relation to the bar deflected axis. Introducing $d s$ given by (47), results:

$$
Q(x)=-\frac{d M}{d s}=\frac{-d M / d x}{\sqrt{1+\phi^{2}(x)}}=\frac{w(\ell-x)+q(\ell-x) \phi(x)}{\sqrt{1+\phi^{2}(x)}}
$$

It is an inclined shear effort, as shown in figure 4-b. The shear deformation caused by it has the same slope, given at the infinitesimal level by:

$$
\frac{d y}{\cos \phi}=\frac{d y}{d x / d s}=\frac{d y}{1 / \sqrt{1+\phi^{2}}}=d y \sqrt{1+\phi^{2}}
$$

On establishing the differential equation of motion for this case, two changes must be performed with relation to equation (16): to introduce $d y / \cos \phi$ given by (49), in place of $d y$, and $Q(x)$ given by (48). On doing so, results:

$$
\frac{d y}{d x} \sqrt{1+\phi^{2}(x)}=\frac{Q(x)}{S}=\frac{w(\ell-x)+q(\boldsymbol{\ell}-x) \phi(x)}{S \sqrt{1+\phi^{2}(x)}}
$$

Thus:

$$
\phi(x)=\frac{d y}{d x}=\frac{w(\ell-x)+q(\ell-x) \phi(x)}{S\left[1+\phi^{2}(x)\right]}
$$

In cases of "bland" geometric nonlinearity, as the ones treated by this work, the rotations $\phi(x)$ present values much lesser than unit; therefore, $\phi^{2}(x)$ may be neglected in face of 1 and equation (51) may be put in the form:

$$
S \phi(x)=w(\ell-x)+q(\ell-x) \phi(x)
$$

Isolating $\phi(x)$ :

$$
\phi(x)=\frac{w(\ell-x)}{S-q(\ell-x)}
$$

Integrating equation (53) in relation to $x$ and applying the condition of zero displacement at support, leads to the displacements function. Integrating again, gives:

$$
Y(x)=\frac{S w}{q^{3}}[S-q(l-x)] \cdot\{\ln [S-q(l-x)]-1\}-\frac{S w}{q^{2}} x \ln (S-q l)-\frac{w}{2 q}\left(l^{2}+x^{2}\right)+C
$$

where $C$ is the integration constant. Applying equation (54) for $x=$ 0 and $x=\ell$, leads to the difference below:

$$
Y(\ell)-Y(0)=\frac{S^{2} w}{q^{3}} \ln \frac{S}{S-q \ell}-\frac{w \ell}{q}\left(\frac{\ell}{2}+\frac{S}{q}\right)
$$

Thus, the bending moment at support can be expressed, substituting equation (55) into (32):

$$
M(0)=\frac{w \ell^{2}}{2}+\frac{S^{2} w}{q^{2}} \ln \frac{S}{S-q l}-w \ell\left(\frac{\ell}{2}+\frac{S}{q}\right)=\frac{S^{2} w}{q^{2}} \ln \frac{1}{1-q \ell / S}-\frac{S w \ell}{q}
$$

Applying the condition expressed by inequality (1) to this bending moment, results:

$$
\frac{1,4 S^{2} w}{1,4^{2} q^{2}} \ln \frac{1}{1-1,4 q \ell / S}-\frac{1,4 S w \ell}{1,4 q} \leq 1,1 \times 1,4 \frac{w \ell^{2}}{2}
$$

Performing the required algebraic transformations, inequality (57) changes into:

$$
\frac{1}{1,4(q \ell / S)^{2}} \ln \frac{1}{1-1,4 q \ell / S}-\frac{1}{q \ell / S} \leq 0,77
$$

Taking the factor q $\ell$ /Sas an unknown, inequality (58) can be solved by means of trials, obtaining:

$$
q \ell / S \leq 0,0962
$$


Substituting $S$ by expression (18), results:

$$
\ell^{2} \cdot q \ell / E J \leq 0,3848
$$

According to the ABNT [8] code, the physical nonlinearity might be considered, substituting $E J$ by $(E I)_{\mathrm{sec}}$ given by (12). However, the $(E I)_{\mathrm{sec}} / E_{\mathrm{cS}} I_{\mathrm{C}}$ ratio of the frame bars assemblage, as a function of the individual bar $(E I)_{\mathrm{sec}} / E_{\mathrm{CS}} I_{\mathrm{C}}$ ratios cannot be considered a constant value; it can vary due to many factors, such as the numbers of floors and spans, story heights, span lengths, relation between the cross section dimensions of beams and columns etc. Pinto and Ramalho [11] show that the influence of physical nonlinearity in the frame lateral stiffness depends mainly on the reinforcement ratios and the loading magnitude; they obtained $(E I)_{\mathrm{sec}} / E_{\mathrm{cS}} I_{\mathrm{c}}$ ratios varying from 0,51 until 0,75 for the ultimate limit state.

On the other hand, Schueler [12] states that the contribution of beams flexibility for the lateral deflections of a rigid frame can reach $65 \%$, remaining $35 \%$ due to columns flexibility. Furthermore, in a slender frame the beam reinforcements $A_{\mathrm{s}}$ and $A_{\mathrm{s}}$ ' tend to be the same, due to the predominance of wind effects. Thus, in this case equations (10) and (11) may be employed to relate the components of $y_{N L}$ (frame horizontal displacements including physical nonlinearity), due to the beams $\left(y_{N L}{ }^{\text {BEAMS }}\right)$ and columns $\left(y_{\mathrm{NL}}{ }^{\text {COLUMNS }}\right)$, with the corresponding components $\left(y_{\mathrm{L}}{ }^{\text {BEAMS }}\right)$ and $\left(y_{\mathrm{L}}{ }_{\mathrm{L}}^{\text {COLUMNS }}\right)$ of the horizontal displacements resulting from linear analysis $\left(y_{L}\right)$. Simultaneously, the above-mentioned share factors $(35 \%$ and $65 \%$ ) of these components in the total displacements may be used, leading to the following expressions:

$$
y_{\mathrm{NL}}^{\text {columNs }}=\frac{y_{\mathrm{L}}^{\text {columNs }}}{0,941}=\frac{0,35 y_{\mathrm{L}}}{0,941}
$$

$$
y_{\mathrm{NL}}^{\mathrm{BEAMS}}=\frac{y_{\mathrm{L}}^{\mathrm{BEAMS}}}{0,588}=\frac{0,65 y_{\mathrm{L}}}{0,588}
$$

Performing the sum of the components expressed by (61) and (62), leads to the following relation between the total horizontal displacements $y_{\mathrm{NL}}$ and $y_{\mathrm{L}}$ :

$$
y_{\mathrm{NL}}=\frac{0,35 y_{\mathrm{L}}}{0,941}+\frac{0,65 y_{\mathrm{L}}}{0,588}=\frac{y_{\mathrm{L}}}{0,677}
$$

As the frame lateral stiffness is inversely proportional to these displacements, it may be written:

$$
(E I)_{\mathrm{sec}}=0,677 E_{C S} I_{C}
$$

Considering this expression of $(E I)_{\mathrm{sec}}$ and following the same deductive sequence that led to the inequalities (45) and (46), results:

$$
H_{\text {tot }} \times \sqrt{N_{\mathrm{k}} / E_{\mathrm{CS}} I_{\mathrm{C}}} \leq 0,51
$$

It can be noticed that this inequality is coherent with ABNT [8] code, which appoints the value of 0,5 for the coefficient $\alpha_{1}$, if the bracing system is constituted exclusively by rigid frames. In fact, in order to obtain $\alpha_{1}=0,5,(E I)_{\text {sec }}$ must satisfy the following:

$$
(E I)_{\mathrm{sec}}=0,650 E_{C S} I_{C}=0,552 E_{C i} I_{C}
$$

\subsection{Associations of rigid frames with shear walls and/or shear cores}

The same model of figure 3 is adopted and the same definitions of section 2.2 are considered. In order to deduce the differential equation of motion for the frames assemblage (figure 3-c), equation (50) is applied, adding the terms due to the wall-frame interaction to the shear effort, as was done in equation (19):

$$
\frac{Q(x)}{S}=\frac{w_{1}(\ell-x)+Q_{T}+\int_{x}^{\ell} u(\xi) d \xi+q_{1}(\ell-x) \phi(x)}{S \sqrt{1+\phi^{2}(x)}}=\phi(x) \sqrt{1+\phi^{2}(x)}
$$

Considering that $\phi^{2}(x)$ may be neglected in face of 1 and isolating the terms due to the interaction forces:

$$
Q_{T}+\int_{x}^{\ell} u(\xi) d \xi=S \phi(x)-w_{1}(\ell-x)-q_{1}(\ell-x) \phi(x) \quad(68)
$$

In order to deduce the differential equation of motion for the walls assemblage (figure 3-b), the bending moment given by (31) is introduced, added to the terms due to the interaction forces, as was done in equation (21):

$$
\frac{w_{2}(l-x)^{2}}{2}-Q_{T}(l-x)-\int_{x}^{l} u(\xi)(\xi-x) d \xi+q_{2}[Y(l)-Y(x)-(\ell-x) y(x)]=\frac{E J_{2} d^{2} y}{d x^{2}}
$$

Deriving equation (69) in relation to $x$, gives:

$$
E J_{2} \frac{d^{3} y}{d x^{3}}=E J_{2} \frac{d^{2} \phi}{d x^{2}}=-w_{2}(\ell-x)+Q_{T}+\int_{x}^{\ell} u(\xi) d \xi-q_{2}(\ell-x) \phi(x)
$$


Substituting (68) into (70) and re-arranging, results:

$$
E J_{2} \frac{d^{2} \phi}{d x^{2}}=-\left(w_{1}+w_{2}\right)(\ell-x)-\left(q_{1}+q_{2}\right)(\ell-x) \phi(x)+S \phi(x)
$$

Considering that $w_{1}+w_{2}=w$ (total wind load), $q_{1}+q_{2}=q$ (total gravity load) and re-arranging again, leads to the differential equation describing the behavior of a system composed by rigid frames and walls/cores, including the deflections influence:

$$
E J_{2} \frac{d^{2} \phi}{d x^{2}}-[S-q(\ell-x)] \phi(x)+w(\ell-x)=0
$$

In order to apply the Galerkin method to equation (72), it will be assumed a solution given by a function $f(x)$ multiplied by the linear solution, expressed by equations (25), (26) and (27):

$$
\phi(x)=f(x)\left[C_{1} e^{2 K x / \ell}+C_{2} e^{-2 K x / \ell}+\frac{w \ell^{2}}{4 E J_{1}}(\ell-x)\right]
$$

Substituting (73) into (72), results:

$$
\begin{aligned}
& E J_{2} f^{\prime \prime}(x)\left[C_{1} e^{2 K x / l}+C_{2} e^{-2 K x \cdot l}+\frac{w^{2}}{4 E J_{1}}(\ell-x)\right]+ \\
& 2 E J_{2} f^{\prime}(x)\left[\frac{2 K}{l}\left(C_{1} e^{2 K x / l}-C_{2} e^{-2 K x \cdot l}\right)-\frac{w l^{2}}{4 E J_{1}}\right]+\frac{4 K^{2}}{l^{2}} E J_{2} f(x)\left(C_{1} e^{2 K x \cdot l}+C_{2} e^{-2 K x \cdot l}\right)- \\
& \left.f(x)[S-q(l-x)] C_{1} e^{2 K x \cdot l}+C_{2} e^{-2 K x \cdot l}+\frac{w l^{2}}{4 E J_{1}}(l-x)\right]+w(l-x)=0
\end{aligned}
$$

Assuming that $f(x)$ is a constant function, leads the first and second terms of equation (74) to be null, since they are multiplied by the derivatives $f^{\prime}(x)$ and $f^{\prime \prime}(x)$. Furthermore, considering the preceding definitions of $K$ (section 2.2) and $S$ (equation 18), it may be written:

$$
\frac{4 K^{2}}{\ell^{2}} E J_{2}=\frac{4 E J_{1}}{\ell^{2}}=S
$$

Consequently, the third term of equation (74) cancels with some parts of the fourth one, reducing the equation to:

$$
q f(x)\left[C_{1} e^{2 K x / \ell}+C_{2} e^{-2 K x / \ell}+\frac{w \ell^{2}}{4 E J_{1}}(\ell-x)\right]+w[1-f(x)]=0
$$

The Galerkin method will be used in order to find a constant function $f(x)$ that has to be a good approximation for $f(x)$ appearing in equation (76). According to (28), it may be written:

$$
\bar{f}(x)=a_{1} \varphi_{1}(x) \quad \ni \quad \varphi_{1}(x)=1
$$

For this case, equation (29) is applied in the following form:

$$
\int_{0}^{l}\left\{a_{1} q\left[C_{1} e^{2 K x l}+C_{2} e^{-2 K x l}+w \ell^{2}(\ell-x) / 4 E J_{1}\right]+w\left(1-a_{1}\right)\right\} d x=0
$$

Performing the integration, $a_{1}$ can be isolated, giving:

$$
a_{1}=\frac{1}{1-\frac{q \ell^{3}}{8 E J_{1}}-\frac{q}{2 K w}\left[C_{1}\left(e^{2 K}-1\right)-C_{2}\left(e^{-2 K}-1\right)\right]}
$$

Therefore, the approximate solution for equation (72) will be given by:

$$
\phi(x)=a_{1}\left[C_{1} e^{2 K x / \ell}+C_{2} e^{-2 K x / \ell}+\frac{w \boldsymbol{\ell}^{2}}{4 E J_{1}}(\ell-x)\right]
$$

with $a_{1}$ given by (79). Integrating twice leads to the primitive of the displacements function:

$$
Y(x)=a_{1}\left[\frac{l^{2}}{4 K^{2}}\left(C_{1} e^{2 K x / \ell}+C_{2} e^{-2 K x / \ell}\right)+\frac{w l^{2} x^{2}}{4 E J_{1}}\left(\frac{\ell}{2}-\frac{x}{6}\right)+C_{3} x+C_{4}\right]
$$

where $C_{4}$ is an undetermined constant and $C_{3}$ results from the condition of zero displacement at support:

$$
C_{3}=\frac{-w \ell^{4}}{8 E J_{1}} \cdot \frac{K\left(e^{4 K}-1\right)+e^{2 K}}{K^{2}\left(e^{4 K}+1\right)}
$$

The bending moment at support is obtained, applying equation (32):

$$
M(0)=\frac{w t^{2}}{2}+a_{1} q\left\{\frac{\ell^{2}}{4 K^{2}}\left[C_{1}\left(e^{2 K}-1\right)+C_{2}\left(e^{-2 K}-1\right)\right]+\frac{w \ell^{5}}{12 E J_{1}}+C_{3} \ell\right\}
$$


It can be observed that the difference $Y(\ell)-Y(0)$ made the constant $C_{4}$ to vanish. Substituting $C_{1}, C_{2}$ and $C_{3}$, respectively, by equations (26), (27) and (82), transforms equation (83) into:

$$
M(0)=\frac{w \ell^{2}}{2}+\frac{a_{1} q w \ell^{5}}{96 E J_{1} K^{3}} \cdot \frac{\left(6 K+8 K^{3}\right)\left(e^{4 K}+1\right)+\left(3-12 K^{2}\right)\left(e^{4 K}-1\right)-24 K e^{2 K}}{e^{4 K}+1}
$$

Introducing the expressions for $C_{1}$ and $C_{2}$ also in equation (79) and substituting the formula of $a_{1}$ obtained in such a manner into equation (84), leads to the expression of the bending moment at support of the system composed by frames and walls/cores:

$$
M(0)=\frac{w l^{2}}{2}\left[1+\frac{\left(2 K+8 K^{3} / 3\right)\left(e^{4 K}+1\right)+\left(1-4 K^{2}\right)\left(e^{4 K}-1\right)-8 K e^{2 K}}{\left(16 E J_{1} / q l^{3}\right) K^{3}\left(e^{4 K}+1\right)-\left(K+2 K^{3}\right)\left(e^{4 K}+1\right)+2 K^{2}\left(e^{4 K}-1\right)+2 K e^{2 K}}\right]
$$

Applying the condition expressed by inequality (1) to this bending moment, results:

$$
\frac{1,4 w l^{2}}{2}\left[1+\frac{\left(2 K+8 K^{3} / 3\right)\left(e^{4 K}+1\right)+\left(1-4 K^{2}\right)\left(e^{4 K}-1\right)-8 K e^{2 K}}{\left(16 E J K_{1}^{3} / 1,4 q q^{3}-2 K^{3}-K\right)\left(e^{4 K}+1\right)+2 K^{2}\left(e^{4 K}-1\right)+2 K e^{2 K}}\right] \leq 1,1, \times \frac{1,4 w l^{2}}{2}
$$

In inequality (86), the factor $q \ell^{3} / E J_{1}$ can be isolated, giving:

$$
\frac{q \ell^{3}}{E J_{1}} \leq \frac{(24 / 7) K^{3}\left(e^{4 K}+1\right)}{\left(6,3 K+8,6 K^{3}\right)\left(e^{4 K}+1\right)+\left(3-12,6 K^{2}\right)\left(e^{4 K}-1\right)-24,6 K e^{2 K}}
$$

Calling $J$ the sum of inertias of the walls/cores and frames assemblages, and considering the preceding definition of $K$, it may be written:

$$
J=J_{1}+J_{2}=J_{1}+J_{1} / K^{2}=J_{1}\left(K^{2}+1\right) / K^{2}
$$

Isolating $J_{1}$ :

$$
J_{1}=K^{2} J /\left(K^{2}+1\right)
$$

$I_{\mathrm{C} 1}$ and $I_{\mathrm{C} 2}$ are defined as the gross inertias, respectively, of the frames and walls assemblages. Calling $I_{\mathrm{C}}$ the sum of $I_{\mathrm{C} 1}$ and $I_{\mathrm{C} 2}$ and applying the relations (11) and (66), gives:

$$
I_{C}=I_{C 1}+I_{C 2}=\frac{J_{1}}{0,65}+\frac{J_{2}}{0,941}=\frac{J_{1}}{0,65}+\frac{J_{1}}{0,941 K^{2}}=\frac{1,5385 K^{2}+1,0625}{K^{2}} J_{1}
$$

Table 1 - Values of $\alpha_{1}$, varying the $I_{C 1} / I_{C}$ ratio

\begin{tabular}{cccccc}
$I_{c 1} / I_{c}$ & $\alpha_{1}$ & $I_{c 1} / I_{c}$ & $\alpha_{1}$ & $I_{c 1} / I_{c}$ & $\alpha_{1}$ \\
0 & 0,773 & 0,50 & 0,755 & 0,90 & 0,651 \\
0,10 & 0,772 & 0,60 & 0,744 & 0,95 & 0,611 \\
0,20 & 0,771 & 0,70 & 0,726 & 0,98 & 0,574 \\
0,30 & 0,768 & 0,80 & 0,699 & 0,99 & 0,555 \\
0,40 & 0,763 & 0,85 & 0,679 & 1,00 & 0,509 \\
\hline
\end{tabular}

From (90), the factor $E J_{1}$ may be expressed by:

$$
E J_{1}=\frac{K^{2}}{1,5385 K^{2}+1,0625} E_{C S} I_{C}
$$

Equation (87) can be rewritten, substituting $E J_{1}$ by expression (91), $q \ell$ by $N_{\mathrm{k}}$ (total vertical load) and $\ell$ by $H_{\text {tot }}$ (building height). After, extracting the square root of both members, results:

$$
H_{t o t} \times \sqrt{\frac{N_{k}}{E_{C S} I_{C}}} \leq \alpha_{1}
$$

where

$$
a_{1}=\sqrt{\frac{(247) K^{5}\left(e^{4 K}+1\right)}{\left.\left(1,3385 K^{2}+1,0625\right)\left(6,3 K+8,6 K^{3}\right)\left(e^{4 K}+1\right)+\left(3-12,6 K^{2}\right)\left(e^{4 K}-1\right)-24,6 K e^{2 K}\right]}}
$$

In this manner, an expression for the limit $\alpha_{1}$ of the instability parameter, variable with $K$ (relation between the reduced inertias of frames and walls/cores), was obtained. However, in order to obtain $\alpha_{1}$, it is more practical to deal with the gross inertias. Combining equations (66) and (90), the following relation between $K$ and $I_{\mathrm{C} 1} I$ $I_{C}$ (proportion between the frames gross inertia and the total one) is obtained:

$$
K=0,831 \sqrt{\left(I_{C 1} / I_{C}\right) /\left(1-I_{C 1} / I_{C}\right)}
$$

Thus, given any proportion $I_{\mathrm{C} 1} I_{\mathrm{C}}, \mathrm{K}$ is obtained applying equation (94); soon after, $\alpha_{1}$ is obtained applying equation (93). The sequence of $\alpha_{1}$ values, presented in table 1 and graphically represented in figures 7 and 8 , shows a rough variation for $I_{\mathrm{C} 1} / I_{\mathrm{C}}$ close to 1 (predominance of frames) and a more smooth one for $I_{\mathrm{C} 1} I_{\mathrm{C}}$ close to 0 (predominance of walls). It can also be observed that equation (93), at its domain ends, reproduces equation (46) exactly, but presents a discrepancy of $1,8 \%$ for bracing systems composed exclusively by rigid frames. The 
Figure 5 - Transversal bracing system: examples 1, 3, 5 and 7

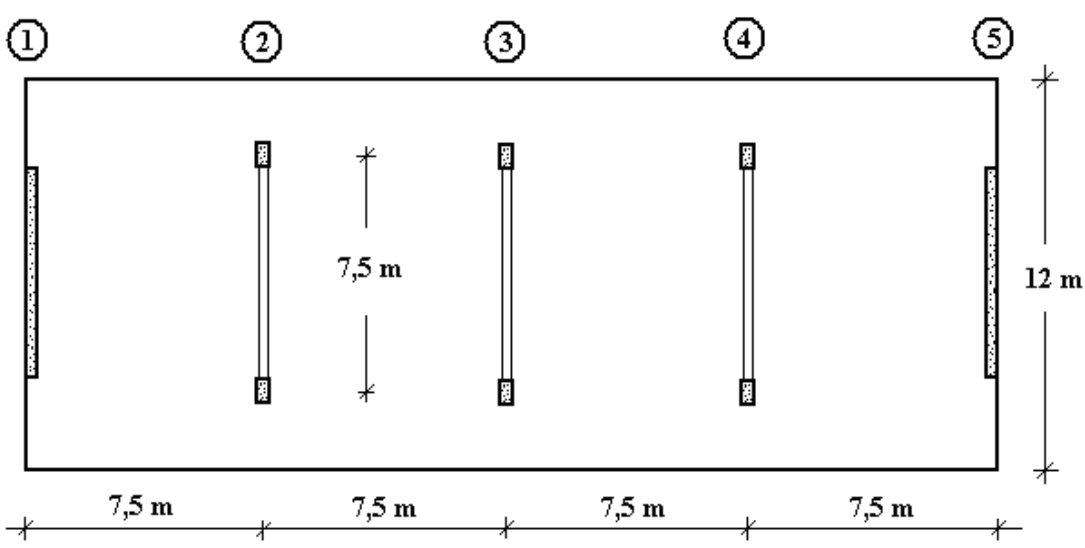

next sections present a series of examples assaying the feasibility of equation (93).

\section{Examples}

\subsection{Description of the tests}

The plan of figure 5 shows the basic configuration of the transversal bracing system of a rectangular on plane building (examples 1 , 3,5 and 7 ); it is constituted by walls 1 and 5 on the lateral faces and the rigid frames 2, 3 and 4 spanning over a single bay $(7,5 \mathrm{~m}$ between column axes). In the same way, figure 6 shows the basic configuration of the transversal bracing system of a building with an oblong octagonal shape on plane (examples 2, 4, 6 and 8); it is also composed by two walls and three frames which, in this case, span over three equal bays ( $5 \mathrm{~m}$ between column axes). Each of these systems was employed in buildings having 5, 10, 20 and 30 floors with a $3 \mathrm{~m}$ height, constituting examples 1 to 8 , whose general information is mentioned in table 2 .

Tests were performed for each of the eight buildings, varying the rectangular cross sections of walls and frame members, in such a way to result the sequence of $I_{\mathrm{C} 1} / I_{\mathrm{C}}$ ratios mentioned in table 3 . In some cases, this required changes in the basic configurations of figures 5 and 6 , but keeping the double symmetry of the bracing system on plane. For $I_{\mathrm{C} 1} I_{\mathrm{C}}=1$, the walls were suppressed; for decreasing values of $I_{\mathrm{C} 1} I_{\mathrm{C}}$, the frames were gradually suppressed, becoming excluded for $I_{\mathrm{C} 1} I_{\mathrm{C}}=0$. In the examples with 30 floors, some additional frames were included in some cases and some additional walls in others. The cross sections dimensions adopted in the tests are listed in table 4.

\section{Figure 6 - Transversal bracing system: examples 2, 4, 6 and 8}

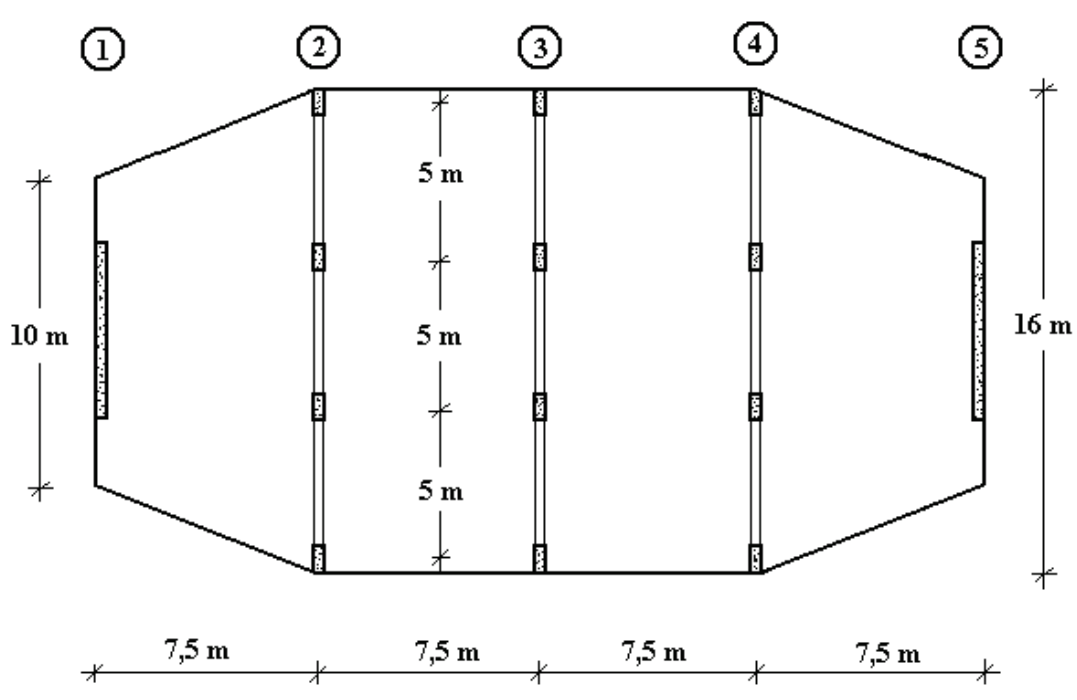




\section{Figure 7 - Graphs $\alpha_{1} \times I_{C_{1}} / I_{C}$ ratio for the examples with 5 and 10 floors}

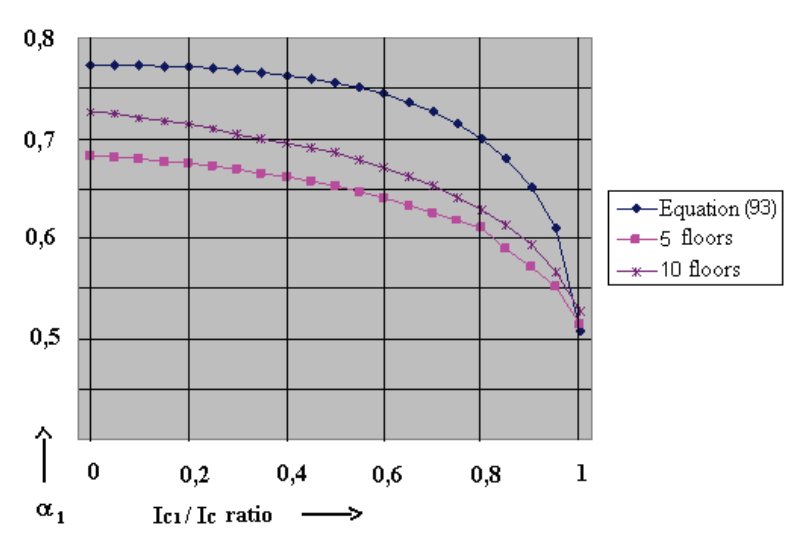

Figure 8 - Graphs $\alpha_{1} \times I_{c 1} / I_{c}$ ratio for the examples with 20 and $\mathbf{3 0}$ floors

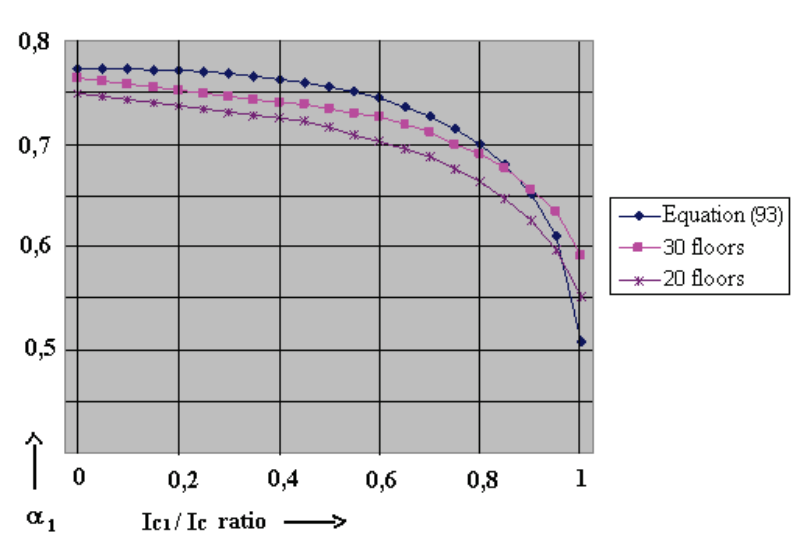

Table 2 - General information about examples 1 to 8

\begin{tabular}{|ccccccccc|}
\hline Example & 1 & 2 & 3 & 4 & 5 & 6 & 7 & 8 \\
\hline Floors number & 5 & 5 & 10 & 10 & 20 & 20 & 30 & 30 \\
Building height $(\mathrm{m})$ & 15 & 15 & 30 & 30 & 60 & 60 & 90 & 90 \\
Spans number perframe & 1 & 3 & 1 & 3 & 1 & 3 & 1 & 3 \\
Frames number & 0 to 3 & 0 to 3 & 0 to 3 & 0 to 3 & 0 to 3 & 0 to 3 & 0 to 5 & 0 to 5 \\
Walls number & 0 to 2 & 0 to 2 & 0 to 2 & 0 to 2 & 0 to 2 & 0 to 2 & 0 to 2 & 0 to 4 \\
\hline
\end{tabular}

Table $3-I_{c_{1}} / I_{c}$ ratios adopted in the examples

\begin{tabular}{|c|c|c|c|c|c|c|c|c|c|}
\hline 1,00 & 0,95 & 0,90 & 0,85 & 0,80 & 0,70 & 0,60 & 0,50 & 0,40 & 0,20 \\
\hline
\end{tabular}

\section{Table 4 - Cross sections dimensions (cm)}

\begin{tabular}{cccc|} 
Example & Beams & Columns & Walls \\
\hline 1 & $20 \times 50$ to $25 \times 60$ & $20 \times 50$ to $25 \times 60$ & $20 \times 88,5$ to $20 \times 201$ \\
2 & $15 \times 34$ to $20 \times 50$ & $15 \times 34$ to $20 \times 50$ & $20 \times 102$ to $20 \times 243$ \\
3 & $18 \times 68$ to $24 \times 68$ & $30 \times 85$ to $40 \times 85$ & $20 \times 158,5$ to $20 \times 422,5$ \\
4 & $15 \times 51$ to $24 \times 59,5$ & $20 \times 77$ to $34 \times 90$ & $20 \times 224$ to $20 \times 481,5$ \\
5 & $34 \times 85$ & $42,5 \times 140$ & $20 \times 307,5$ to $25 \times 838,5$ \\
6 & $21 \times 68$ & $34 \times 96$ & $20 \times 351$ to $25 \times 957$ \\
7 & $34 \times 85$ & $42,5 \times 140$ & $20 \times 418$ to $35 \times 1200$ \\
8 & $21 \times 85$ & $36 \times 119$ & $20 \times 588$ to $31 \times 998,5$ \\
\hline
\end{tabular}

A concrete with $f_{c k}=25 \mathrm{MPa}$ was adopted, resulting in an elasticity modulus $\mathrm{E}_{\mathrm{CS}}=23800 \mathrm{MPa}$. A total vertical load of $10 \mathrm{kN} / \mathrm{m}^{2}$ per floor (characteristic value) was considered. A wind pressure of $1,5 \mathrm{kN} / \mathrm{m}^{2}$ (characteristic value), constant along the height, was adopted, since it was the first experience with a formulation based on a model with constant wind load. 
Table 5 - Values of $\alpha_{1}$, varying the $\mathrm{I}_{\mathrm{Cl}} / \mathrm{I}_{\mathrm{C}}$ ratio and the numbers of floors and spans

\begin{tabular}{|c|c|c|c|c|c|c|c|c|c|}
\hline $\mathrm{I}_{\mathrm{Cl}} / \mathrm{I}_{\mathrm{c}}$ & $\begin{array}{l}\text { Example: } \\
\text { Floors: }\end{array}$ & $\begin{array}{l}1 \\
5\end{array}$ & $\begin{array}{l}2 \\
5\end{array}$ & $\begin{array}{c}3 \\
10\end{array}$ & $\begin{array}{c}4 \\
10\end{array}$ & $\begin{array}{c}5 \\
20\end{array}$ & $\begin{array}{c}6 \\
20\end{array}$ & $\begin{array}{c}7 \\
30\end{array}$ & $\begin{array}{c}8 \\
30\end{array}$ \\
\hline 1,00 & & 0,515 & 0,514 & 0,528 & 0,519 & 0,569 & 0,534 & 0,608 & 0,591 \\
\hline 0,95 & & 0,552 & 0,557 & 0,567 & 0,563 & 0,605 & 0,590 & 0,639 & 0,635 \\
\hline 0,90 & & 0,572 & 0,584 & 0,594 & 0,592 & 0,630 & 0,621 & 0,656 & 0,656 \\
\hline 0,85 & & 0,590 & 0,603 & 0,613 & 0,614 & 0,650 & 0,644 & 0,675 & 0,676 \\
\hline 0,80 & & 0,610 & 0,619 & 0,629 & 0,632 & 0,663 & 0,662 & 0,690 & 0,690 \\
\hline 0,70 & & 0,626 & 0,641 & 0,653 & 0,657 & 0,687 & 0,687 & 0,710 & 0,711 \\
\hline 0,60 & & 0,641 & 0,656 & 0,671 & 0,676 & 0,702 & 0,702 & 0,724 & 0,727 \\
\hline 0,50 & & 0,652 & 0,665 & 0,685 & 0,689 & 0,716 & 0,716 & 0,734 & 0,735 \\
\hline 0,40 & & 0,662 & 0,671 & 0,695 & 0,699 & 0,724 & 0,726 & 0,743 & 0,740 \\
\hline 0,20 & & 0,675 & 0,681 & 0,714 & 0,715 & 0,738 & 0,736 & 0,753 & 0,752 \\
\hline 0 & & 0,683 & 0,683 & 0,726 & 0,726 & 0,749 & 0,749 & 0,764 & 0,764 \\
\hline
\end{tabular}

Thus, 88 different bracing systems were tested. Each test aimed to determine the relation between vertical loads and horizontal stiffness that would result in a $10 \%$ increase on the global bending moment at building support, concerning to first order analysis; in this way, the limit $\alpha_{1}$ for the instability parameter was determined. The procedure applied in each test consisted in, at first, to assign cross section dimensions for the members of the frames assemblage and compute its horizontal stiffness $I_{\mathrm{C} 1}$, according to item 15.5.2 of ABNT [8] code (relation between the wind load and the horizontal displacement at structure top). After, the cross section of the walls assemblage was adjusted in order to obtain the desired $I_{\mathrm{C} 1} / I_{\mathrm{C}}$ ratio.

The test proceeded with an initial second order analysis of the frame-wall system, employing the $P$ - $\Delta$ method. After, this second order analysis was successively repeated, adjusting the values of the vertical loads, until achieving the desired $10 \%$ increase on the support global moment. Although an adjustment of the horizontal stiffness would be more logical, the loads adjustment was preferred because it made the 88 tests more agile to perform and didn't affect the results. The physical nonlinearity was considered by means of the individual bar stiffness reductions expressed by equations (10) and (11). The analysis was performed using the same plane frame model of figure 3 , with the sets of frames and walls joined by hinges, since the formulation proposed in this work is based just on that model. Later on, some cases were reanalyzed by means of a method employing geometric stiffness matrices, in order to confirm the results obtained by $P-\Delta$ method.

\subsection{Results discussion}

The values of $\alpha_{1}$ obtained in the tests are listed in table 5 . In order to better interpret the results, it is appropriate to arrange the eight examples according to the floors number and to consider two ranges of the relative stiffness values: $I_{\mathrm{C} 1} / I_{\mathrm{C}} \leq 0,9$ and $I_{\mathrm{C} 1} I_{\mathrm{C}}>0,9$. Figures 7 and 8 show, for each floors number, a graph representing the variation of the parameter $a_{1}$ found in the tests, as well as the graph of $\alpha_{1}$ corresponding to formula (93).

On examining the results regarding to $I_{\mathrm{C} 1} I_{\mathrm{C}} \leq 0,9$, it is verified that almost all the values for $\alpha_{1}$ obtained in the examples are below the values predicted by formula (93) and listed in table 1 . Thus, the application of this formula results in upward errors, whose maximum values are mentioned in table 6 . It can be clearly observed that these errors decrease as the number of floors increases; they are of $16,2 \%$ at 5 floors and drop to $3,1 \%$ at 30 floors, indicating a trend to become null for a little more than 30 floors. This behavior of equation (93) is much probably due to the adoption of figure 1-b model, in place of figure 1-a one; in other words, the model with an uniform and continuous distribution of floors and vertical loads provides a reasonable accuracy only for buildings with more than 30 floors.

On the other hand, for values of $I_{\mathrm{C} 1} / I_{\mathrm{C}}$ larger than 0,9 , indicative of a high predominance of frames, the trend of decreasing errors with the increase of floors also exists. However, in this case, it comes along with another trend, consisting of downward errors generated by equation (93), increasing with the floors number, as can be

Table 6 - Maximum errors (\%)

\begin{tabular}{lcccc}
$\mathrm{I}_{\mathrm{Cl}} / \mathrm{I}_{\mathrm{c}}$ & 5 filoors & 10 floors & 20 floors & 30 floors \\
$\leqslant 0,90$ & $+16,2$ & $+11,2$ & $+6,0$ & $+3,1$ \\
$=0,95$ & $+10,7$ & $+8,5$ & $+3,6$ & $-4,4$ \\
$=1,00$ & $-1,2$ & $-3,6$ & $-10,5$ & $-16,3$ \\
\hline
\end{tabular}


observed in table 6 for $I_{\mathrm{C} 1} I_{\mathrm{C}}=0,95$ and 1,00 . This trend is due to equation (93) taking into account that the frames distort only due to global shear. Smith and Coull [13] state that, in slender buildings, the frames global bending, due to the columns axial deformation, can contribute significantly to the horizontal displacements. It is about the same distortion pattern of walls, making the limit coefficient $\alpha_{1}$ to increase. Thus, as much higher the building and the greater presence of frames, greater will be the errors generated by a formulation that neglects this effect. In the case of bracing systems composed exclusively by frames $\left(I_{\mathrm{C} 1} I_{\mathrm{C}}=1\right)$, table 6 shows maximum errors varying between $-1,2 \%$ ( 5 floors) and $-16,3 \%$ (30 floors).

Still regarding to the case $I_{C_{1}} I_{\mathrm{C}}=1$, the values of $\alpha_{1}$ mentioned in the first line of table 5 hint that the limit $\alpha_{1}=0,5$, prescribed by ABNT [8] for bracing systems composed exclusively by frames, is conservative, especially in buildings with more than 10 floors. On the other hand, the values of $a_{1}$ found for $I_{\mathrm{C}_{1}} / I_{\mathrm{C}}=0$, mentioned in the last line of table 5 , indicate that the limit $\alpha_{1}=0,7$, prescribed for bracing systems composed exclusively by walls/cores, is also conservative for buildings with more than 10 floors. However, in buildings with less than 10 floors, the contrary can occur; values slightly lower than 0,7 were found in buildings with 5 floors. Furthermore, the adoption of the fixed value $\alpha_{1}=0,6$ for wall-frame and coreframe bracing systems should be conditioned to a minimum limit of the walls contribution for the bracing stiffness, especially in lower buildings. Interpolations performed in the values of table 5 indicate that the proportion of the walls gross inertia in relation to the total one should be at least $18 \%$ in example $1,14 \%$ in example 2 and $12 \%$ in examples 3 and 4 .

\section{Conclusions}

The limit values $\alpha_{1}$ for the instability parameter, obtained in the examples of this work and mentioned in table 5 , vary from a minimum of 0,514 in example 2 until a maximum of 0,764 in examples 7 and 8 . The proportion between these extreme values is close to $1,5: 1$. Since their computation includes a square root extraction, the proportion between the radicands (vertical load/horizontal stiffness relations) associated to these extreme values is more than $2: 1$. The extent of this variability shows the importance of having a way of predicting a limit $\alpha_{1}$ appropriated to the relation $I_{\mathrm{C} 1} / I_{\mathrm{C}}$ and the floors number of a given building to be designed, in place of the fixed values prescribed by ABNT [8]

Equation (93) represents an initial attempt to accomplish such prediction. The relatively good accuracy attained in examples 7 and 8 for $I_{\mathrm{C} 1} I_{\mathrm{C}} \leq 0,9$ denotes that this aim is possible to be achieved and efforts deserve to be done in order to carry it out. In order to remedy the errors occurred in the other cases (predominance of frames and low number of floors), the effect of the columns axial flexibility has to be introduced into equations (16) and (50), making the curve of $\alpha_{1}$, corresponding to equation (93) and depicted in figures 7 and 8 , decline not so much in its final segment; it has also to be searched a way to adjust the formulation to the variation of the floors number. Another subject to investigate is the viability of including the variability of physical nonlinearity influence in the frames horizontal stiffness (actually, this influence is considered through a constant factor).

It must be emphasized that all of this has to be done in such a manner to keep the formulation simplicity, just one of the greater advantages of the instability parameter utilization. Finally, it must be ac- centuated the need of adopting a more realistic analysis model for the tests: modeling of the structure as a three-dimensional frame, considering the floors as rigid diaphragms; variation of the wind load along the building height; effectuation of the nonlinear analysis through an incremental-iterative method; and a more accurate consideration of physical nonlinearity, for example, by means of moment-curvature relations.

\section{Acknowledgment}

I would like to thank Prof. Eng. Mário Franco, for providing precious material for this work achievement.

\section{References}

[01] Beck, H. and König, G.; Haltekräfte im Skeletbau. In: Beton- und Stahlbetonbau, n. 62, tome 1 (pp. 7-15) and tome 2 (pp. 37-42), Berlin, 1967.

[02] CEB - Comité Euro-International du Béton; CEB/FIP Manual of Buckling and Instability, The Construction Press, Lancaster, 1978.

[03] Vasconcelos, A.C.; Origem dos Parâmetros de Estabilidade $\alpha$ e $\gamma_{z}$. In: Revista IBRACON de Estruturas, n. 20, pp. 56-60, São Paulo, 1998.

[04] Sussekind, J.C.; Curso de Concreto, vol. 2, Porto Alegre, Ed. Globo, 1984.

[05] Franco, M.; Problemas de Estabilidade nos Edifícios de Concreto Armado. In Colóquio IBRACON sobre Estabilidade Global das Estruturas de Concreto Armado, São Paulo, 1985.

[06] Franco, M.; Global and Local Instability of Concrete Tall Buildings, In: International Symposium for Shell and Spatial Structures, Proceedings, vol. 2, pp. 1327-36, Milan, 1995.

[07] Franco, M. and Vasconcelos, A.C.; Practical Assessment of Second Order Effects in Tall Buildings. In: Colóquio do CEB-FIP Model Code 1990, pp. 307-24, Rio de Janeiro, 1991.

[08] ABNT - Associação Brasileira de Normas Técnicas; NBR 6118 - Projeto de Estruturas de Concreto Procedimento, Rio de Janeiro, 2007.

[09] Stamato, M.C.; Associação Contínua de Painéis de Contraventamento (Publicação 157), São Carlos, EESC/USP, 1972.

[10] Kantorovich, L.V. and Krylov, V.I.; Approximate Methods of Higher Analysis, New York, Interscience Publishers Inc., 1964.

[11] Pinto, R.S. and Ramalho, M.A.; Inércia equivalente das estruturas de contraventamento de edifícios em concreto armado. In: Cadernos de Engenharia de Estruturas, São Carlos, v. 9, n. 38, p. 107-136, 2007.

[12] Schueler, W.; High-rise Building Structures, New York, John Wiley \& Sons, 1977.

[13] Stafford Smith, B. and Coull, A.; Tall Building Structures: Analysis and Design, New York, John Wiley \& Sons Inc., 1991. 